\title{
AIDS-Related Malignant Anal Neoplasm
}

National Cancer Institute

\section{Source}

National Cancer Institute. AIDS-Related Malignant Anal Neoplasm. NCI Thesaurus. Code C5047

A malignant neoplasm arising from the anus and occurring in HIV-positive patients.

Representative examples include squamous cell carcinoma and non-Hodgkin lymphoma.

Homosexual HIV-positive men have an increased risk of developing such malignancies in comparison to the general male population. 